\title{
TELAAH POTENSI KAMPUNG SEBAGAI DASAR PERANCANGAN PUSAT KEBUDAYAAN KAMPUNG PANDEYAN
}

\author{
Arti Setyawati ${ }^{1}$, Endah Tisnawati ${ }^{2}$ \\ 1,2. Program Studi Arsitektur, Fakultas Sains dan Teknologi, Universitas Teknologi Yogyakarta, \\ Jl. Glagahsari No. 63, Yogyakarta \\ Email: ${ }^{1}$ setya.arti@gmail.com, ${ }^{2}$ endah.tisnawati@uty.ac.id
}

\begin{abstract}
Abstrak
Yogyakarta merupakan provinsi dengan beragam keistimewaan. Yogyakarta mempunyai banyak sejarah baik sejarah fisik maupun sejarah non fisik. Banyak orang mengenal Yogyakarta sebagai kota budaya dan kota pelajar. Keragaman budaya di Yogyakarta menjadi salah satu daya tarik wisata. Wisatawan tidak hanya mengunjungi objek wisata dan bangunan peninggalan sejarah yang ada namun juga tertarik untuk mengikuti atmosfer budaya yang tidak ditemukan di tempat lain dan berbeda dengan keseharian wisatawan. Meningkatnya minat wisatawan mengenal budaya di kampung tidak diimbangi dengan fasilitas yang mewadahi. Masih minimnya tempat bagi masyarakat dan seniman dalam mengapresiasikan potensi seni dan budaya sekaligus mengedukasi warga masyarakat, sehingga perlu adanya pusat kebudayaan yang berfungsi untuk mengapresiasikan karya seni dan budaya. Kampung Pandeyan saat ini telah berkembang menjadi kampung yang mulai dikenal dengan keragaman potensi seni dan budayanya. Tinjauan potensi kampung yang beragam menjadi dasar desain. Naskah ilmiah ini akan membahas beragam potensi kampung yang digunakan sebagai dasar perencanaan sebuah pusat kebudayaan di Kelurahan Pandeyan. Pusat kebudayaan kampung sendiri merupakan wacana yang ingin ditinjau sebagai fungsi spesifik yang berbeda dengan pusat kebudayaan pada umumnya. Permasalahan yang akan diuraikan yaitu bagaimana perancangan pusat kebudayaan kampung Pandeyan beradasar potensi kampungnya? Hasil desain dari perancangan ini adalah mendesain pusat kebudayaan Kampung Pandeyan sebagai fasilitas bagi masyarakat sekitar dalam pelestarian atraksi seni dan budaya yang ada. Konsep diharapkan dapat diterapkan pada bentuk dan tatanan gubahan massa, hubungan ruang-ruang (baik ruang dalam maupun ruang luarnya), serta penerapan ornamen pada elemenelemen ruang dalam dan ruang luar.
\end{abstract}

Kata kunci: pusat kebudayaan, potensi kampung, arsitektur edukasi.

\section{Abstract \\ Title: The Study of Kampung's Strenght as the Basis for Cultural Center Design at Kampung Pandeyan}

Yogyakarta is a province with various privileges. Yogyakarta has a lot of history both physical history and non-physical history. Many people know Yogyakarta as a cultural city and student city. Cultural diversity in Yogyakarta is one of the tourist attractions. Travelers not only visit tourist attractions and historical heritage buildings but also are interested in following a cultural atmosphere that is not found elsewhere and is different from the daily lives of tourists. The increasing interest of tourists in knowing the culture in the village is not matched by accommodating facilities. There is still a lack of space for people and artists to appreciating art and culture while educating citizens of the community, so there needs to be a cultural center that serves to appreciate works of art and culture. Pandeyan village has now developed into a village that has begun to be known for its diversity of artistic and cultural potential. An overview of the diverse potential of the village is the basis of design. This scientific paper will discuss the various potentials of the village which are used as the basis for planning a cultural center in Pandeyan Village. The village's cultural center itself is a discourse that wants to be reviewed as a specific 
function that differs from the center of culture in general. The problem that will be described is how is the design of the Pandeyan village cultural center based on the potential of the village? The design results of this design are designing the cultural center of Pandeyan Village as a facility for the surrounding community in preserving existing art and cultural attractions. The concept is expected to be applied to the form and order of mass composition, the relationship of spaces (both inner and outer space), and the application of ornaments to the elements of inner and outer space.

Keywords: cultural center, kampung's strenght, educating architecture.

\section{Pendahuluan}

Yogyakarta mempunyai banyak sejarah baik sejarah fisik maupun sejarah non fisik. Kebudayaannya masih berkembang pesat dan bahkan menjadi pusat seni budaya Jawa. Unsur seni budaya masih kental dan bertahan di tengah masyarakat, khusunya pada kampung-kampung di Kota Yogyakarta, salah satunya di Kampung Pandeyan. Kampung ini memiliki berbagai kegiatan seni budaya yang rutin di gelar oleh masyarakat dan menarik minat wisatawan untuk melihat serta ikut menikmati atmosfernya. Kondisi ini juga didukung dengan aktifnya kelompok masyarakat yang peduli terhadap kegiatan seni budaya berbasis kampung. Hal ini ditandai dengan pembentukan kelompok Sigap Karya Budaya sejak bulan Juli 2018. Kelompok ini berkewajiban menjalankan peran dalam pelestarian budaya di Kelurahan Pandeyan. Kelompok peduli budaya ini juga mendapat dukungan penuh dari pemerintah.

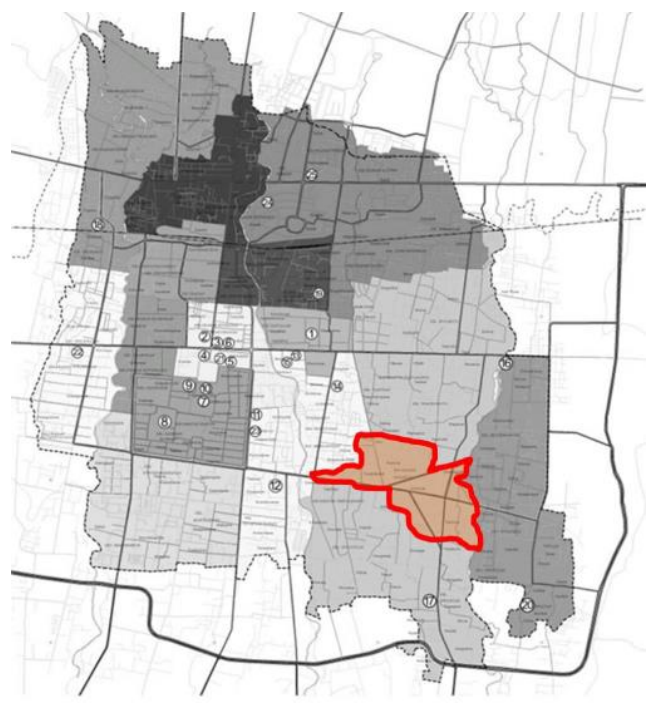

\section{Gambar 1. Posisi Kel. Pandeyan terhadap Kota Yogyakarta \\ Sumber: Dokumentasi penulis, 2018}

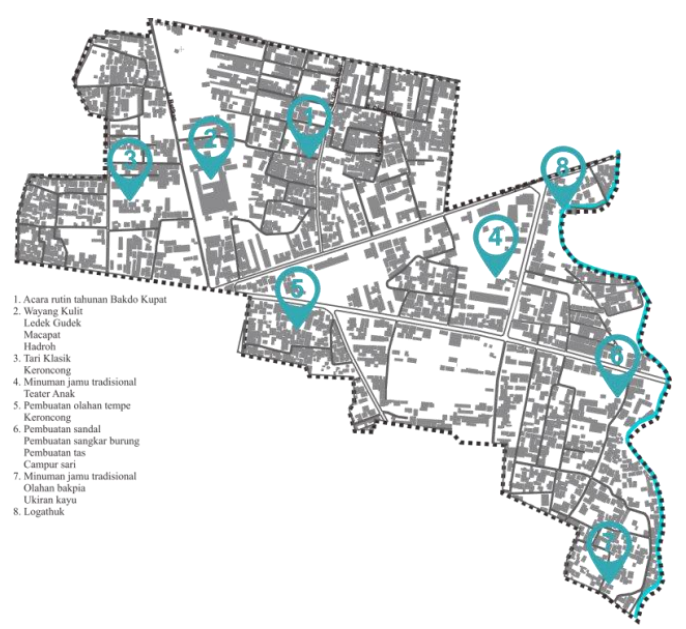

Gambar 2. Peta sebaran seni budaya Kampung Pandeyan

Sumber: Hasil analisis, 2018

Gambar 2 menjelaskan keragaman kegiatan seni budaya di Kampung Pandeyan dan persebarannya di 
beberapa titik. Banyaknya kegiatan seni budaya tidak didukung dengan ketersediaan fasilitas yang mewadahi, sehingga kegiatan yang ada masih bersifat partisipatoris dan belum tertata dengan baik.

Pendekatan desain yang digunakan dalam penyelesaikan desain perancangan pusat kebudayaan yaitu edukasi. Hal ini sesuai dengan visi misi kota Yogyakarta tentang pendidikan dan kebudayaan serta predikat kota Yogyakarta yang dikenal dengan Kota Pelajar. Edukasi dan kebudayaan saling berhubungan erat karena keduanya memiliki kesinambungan dan saling mendukung satu sama lainnya. Menurut Sampouw,Sondakh, dan Supardjo (2016), edukasi atau pendidikan bisa diperoleh dari banyak sarana baik secara formal yaitu sekolah, maupun nonformal yaitu membaca, menonton film, mendengarkan musik, bahkan melalui bersosialisasi. Pendidikan merupakan unsur yang penting untuk meningkatkan sumber daya manusia. Semakin tinggi pendidikan seseorang, maka akan tercermin tingkah laku, budi pekerti, serta cara pandang yang luas dibandingkan dengan orang yang berpendidikan lebih rendah.

\section{Metode Penelitian}

Penulisan makalah ini menggunakan metode deskriptif. Metode ini diharapkan dapat memberikan gambaran tentang permasalan yang ada, kemudian dilakukan analisis untuk mendapatkan suatu perencanaan yang sesuai dengan permasalah yang terjadi (Sugiyono, 2009).

Dalam pengumpulan data perencanaan pusat kebudayaan di Kampung
Pandeyan digunakan beberapa teknik pengumpulan data, diantaranya yaitu:

a. Studi pustaka, diperoleh melalui studi literatur ataupun data dari instansi terkait.

b. Wawancara, dilakukan dengan pihak-pihak yang terkait seperti masyarakat, ataupun ketua kampung wisata.

c. Observasi, dilakukan untuk mengamati obyek secara langsung.

d. Studi kasus, telaah terhadap beberapa obyek yang sama sesuai dengan judul yang diangkat.

\section{Hasil dan Pembahasan}

\section{Potensi Kampung Pandeyan}

Kampung Pandeyan tahun 2018 mewakili Yogyakarta dalam Festival Kampung Wisata di Kulonprogo. Sesuai indikator dalam SK Gubernur No. 36 Tahun 2014, Kampung Wisata Pandeyan merupakan salah satu kampung wisata budaya. Indikator kampung budaya diantaranya: keberadaan adat dan tradisi, potensi seni budaya, permainan anak tradisional, kuliner, kerajinan, obatobat tradisional, konservasi bahasa, sastra dan aksara jawa dan tata ruang serta bangunan cagar budaya atau warisan budaya. Data terkait dengan Kampung Wisata Pandeyan sebagai kampung wisata budaya dapat dilihat pada tabel 1 .

Keberagaman seni budaya dan upaya masyarakat dalam mempertahankan potensi yang dimilikinya menjadi alasan dipilihnya Kampung Wisata Pandeyan sebagai pengembangan konsep tugas akhir. Potensi yang telah dimiliki Pandeyan tidak diimbangi dengan fasilitas yang mewadahi sehingga mengakibatkan pelaksanaan kegiatan atraksi seni budaya tersebar di beberapa titik. Tersebarnya atraksi seni budaya mengakibatkan kurang 
efektifnya kegiatan yang terselenggara. Dengan adanya perancangan pusat kebudayaan di Kampung Wisata Pandeyan diharapkan dapat menampung kegiatan atraksi seni budaya dan beberapa usaha masyarakat yang terkait dengan kebudayaan setempat pada satu lokasi yang mudah dicapai.

Pada tahun 2011 di Kelurahan Pandeyan dibangun sebuah direktori pusat seni dan kerajinan Yogyakarta, yang sering disebut XT Square. XT
Square berfungsi sebagai tempat penjualan hasil seni dan kerajianan. Di dalamnya terdapat fasilitas kios untuk kerajinan dan kuliner, namun pada kenyataanya XT Square menjadi galeri seni 3D dan dikenal sebagi pusat jual beli batu akik. Pada akhirnya, keberadaan XT Square tidak mewadahi seni budaya yang ada di sekitar Kampung Pandeyan, sehingga perlu adanya suatu pusat kebudayaan untuk menampung berbagai macam budaya yang tersebar.

Tabel 1. Potensi Pandeyan sebagai kampung wisata budaya

\begin{tabular}{|c|c|c|c|}
\hline No & Indikator & Kegiatan & $\begin{array}{r}\text { Lokasi } \\
\end{array}$ \\
\hline \multirow[t]{2}{*}{1} & \multirow[t]{2}{*}{ Adat dan tradisi } & Bergodo & Kawasan Kel. Pandeyan \\
\hline & & Bakdo Kupat & Kawasan Kel. Pandeyan \\
\hline \multirow[t]{10}{*}{2} & \multirow[t]{10}{*}{ Potensi seni budaya } & Keroncong & Berpindah \\
\hline & & Congdut & Berpindah \\
\hline & & Tari klasik & Balai RW 02 \\
\hline & & Karawitan & Rumah Bpk. Teguh RW 02 \\
\hline & & Wayang kulit & Balai RW 03 \\
\hline & & Ketoprak Krido Mudobudaya & Berpindah \\
\hline & & Hadroh & Rumah Ibu Ekobudari RW 03 \\
\hline & & Jatilan & Berpindah \\
\hline & & Ledek Gugek & Rumah Drs. Budi Prasojo RW 03 \\
\hline & & Campursari & Berpindah \\
\hline 3 & $\begin{array}{l}\text { Permainan anak } \\
\text { tradisional }\end{array}$ & Teater anak & Berpindah \\
\hline \multirow[t]{9}{*}{4} & \multirow{9}{*}{$\begin{array}{l}\text { Kuliner, kerajinan } \\
\text { dan obat tradisional }\end{array}$} & Jamu tradisional & RW 05, RW 10, RW 11 \\
\hline & & Bakpia 145 & RW 11 \\
\hline & & Bakpia ubi ungu & RW 11 \\
\hline & & Angkringan & RW 10, RW 11 \\
\hline & & Pengrajin tempe & RW 06 \\
\hline & & Pembuatan sandal & RW 13 \\
\hline & & Pembuatan sangkar burung & RW 13 \\
\hline & & Ukir kayu & RW 11 \\
\hline & & Pembuatan tas & RW 13 \\
\hline \multirow[t]{2}{*}{5} & \multirow{2}{*}{$\begin{array}{l}\text { Konservasi bahasa, } \\
\text { sastra dan aksara } \\
\text { Jawa }\end{array}$} & Dagelan Matram & Berpindah \\
\hline & & Macapat & Rumah Bpk. Mugio RW 03 \\
\hline \multirow[t]{4}{*}{6} & \multirow[t]{4}{*}{ Warisan budaya } & Tegal Watu & Kelurahan Pandeyan \\
\hline & & Tirto Wening & Kelurahan Pandeyan \\
\hline & & Logathuk & Kelurahan Pandeyan \\
\hline & & Tapak Tirto & Kelurahan Pandeyan \\
\hline
\end{tabular}

Sumber: Survey lapangan, 2018

Ditandai dengan upaya pemerintah dalam memberikan dana kebudayaan kepada kampung wisata di Yogyakarta, maka terjadi upaya masyarakat dengan membuat organisasi "SIGAP KARYA BUDAYA" sebagai sebuah organisasi 
budaya di kelurahan yang dinamis dan multi potensi yang berkewajiban menjalankan peran dalam pelestarian budaya di Kelurahan Pandeyan.

Sedangkan perancangan pusat kebudayan Kampung Wisata Pandeyan dapat berfungsi sebagai tempat untuk mengenalkan, menjaga, mempertahankan dan mengajarkan kepada masayarakat luas tentang seni budaya yang ada di Pandeyan sebagai wisata berbasis budaya di Yogyakarta.

\section{Telaah Umum Pusat Kebudayaan}

Kebudayaan adalah keseluruhan yang kompleks, yang di dalamnya terkandung ilmu pengetahuan, kepercayaan, kesenian, moral, hukum, adat-istiadat dan kebiasaan yang didapat oleh anggota masyarakat (Tylor, 2012). Menurut Kamus Besar Bahasa Indonesia, pusat kebudayaan adalah tempat membina dan mengembangkan kebudayaan. Sedangkan menurut Budianto (2012), pusat kebudayan adalah tempat membina dan mengembangkan kebudayaan, organisasi, bangunan atau kompleks yang mempromosikan budaya dan seni. Menurut Ramdini, Sarihati, dan Salayanti (2015), terdapat berbagai fungsi dalam sebuah pusat kebudayaan, yaitu administratif, edukasi dan pendidikan, rekreasi dan hiburan, serta fungsi informasi.

Bangunan pusat kebudayaan yang telah terbangun di Indonesia diantaranya adalah Taman Ismail Marzuki (TIM) dan Taman Budaya Yogyakarta (TBY). Keduanya merupakan pusat kebudayaan yang berhasil diwujudkan sesuai dengan fungsi utamanya. Keduanya memiliki fasilitas yang mewadahi seperti: concert hall, amphitheatre, gallery dan beberapa fasilitas pendukung lainnya. Taman Ismail Marzuki dan Taman Budaya Yogyakarta juga memiliki beberapa masa bangunan yang berbeda sehingga variasi ruang yang ditampilkan akan beragam. Hal tersebut didukung dengan penataan sirkulasi dan zonasi yang jelas, juga bentuk masa bangunan yang selaras dengan lingkungan sekitarnya.

Tabel 2. Kesimpulan Studi Kasus

\begin{tabular}{|c|c|c|}
\hline & Taman Budaya Yogyakarta & Taman Ismail Marzuki \\
\hline 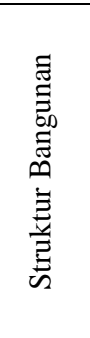 & $\begin{array}{l}\text { Fasade bangunan penuh dengan kolom } \\
\text { besar bergaya kolonial. }\end{array}$ & $\begin{array}{l}\text { Struktur bangunan Toraja sekaligus } \\
\text { Joglo merupakan perpaduan yang unik. }\end{array}$ \\
\hline 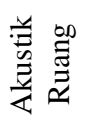 & $\begin{array}{l}\text { Terdapat sistem akustik ruang dan } \\
\text { pencahayaan yang baik di setiap ruang } \\
\text { pertunjukan. }\end{array}$ & $\begin{array}{l}\text { Didukung sistem akustik ruang dan } \\
\text { pencahayaan yang memadai di setiap } \\
\text { ruang pertunjukan. }\end{array}$ \\
\hline 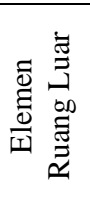 & $\begin{array}{l}\text { Terdapat area hijau berupa pepohonan } \\
\text { mengelilingi bangunan dan public space } \\
\text { yang berfungsi sebagai area pertunjukan } \\
\text { outdoor. }\end{array}$ & $\begin{array}{l}\text { Tatanan lansekap berupa ruang hijau, } \\
\text { berfungsi sebagai resapan air hujan dan } \\
\text { juga menciptakan iklim mikro. Area ini } \\
\text { juga berfungsi sebagai area pertunjukan } \\
\text { outdoor. }\end{array}$ \\
\hline
\end{tabular}




\begin{tabular}{|c|c|c|}
\hline 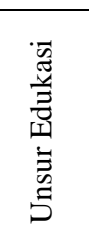 & $\begin{array}{l}\text { Terdapat perpustakaan yang memiliki nilai } \\
\text { edukasi. Terdapat pula ruang khusus untuk } \\
\text { anak dalam mempelajari berbagai seni } \\
\text { budaya Yogyakarta. }\end{array}$ & $\begin{array}{l}\text { Disediakan fasilitas yang menunjang } \\
\text { edukasi, seperti galeri cipta yang dapat } \\
\text { digunakan sebagai ruang pameran, } \\
\text { maupun workshop. Terdapat pula panel } \\
\text { informasi tentang budaya Jakarta sebagai } \\
\text { informasi pengunjung. }\end{array}$ \\
\hline 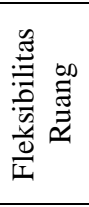 & $\begin{array}{l}\text { Ruang Pameran pada gedung lantai } 1 \\
\text { concert hall taman budaya dapat menadi } \\
\text { ruang yang fleksibel, digunakan sesuai } \\
\text { kebutuhannya. Ukuran ruang dapat diatur, } \\
\text { besar atau kecil. }\end{array}$ & $\begin{array}{l}\text { Ruang pameran dapat difungsikan juga } \\
\text { sebagai ruang workshop. Ruang pameran } \\
\text { menjadi fleksibel saat digunakan untuk } \\
\text { pameran besar dan kecil. Ruangan dapat } \\
\text { disekat sehingga berubah ukuran. }\end{array}$ \\
\hline
\end{tabular}

Sumber: Hasil analisis, 2018

\section{Analisis Program Ruang dan Site}

Bangunan publik yang baik harus mempertimbangkan aspek pengguna dan kapasitasnya. Dengan demikian, pusat kebudayaan ini menyediakan fasilitas dan ruang yang cukup untuk 500 orang per harinya. Sebagian besar penggunanya adalah wisatawan, baik lokal maupun mancanegara. Hal ini didukung dengan ruang-ruang yang beragam dan memiliki zonanya masing-masing.

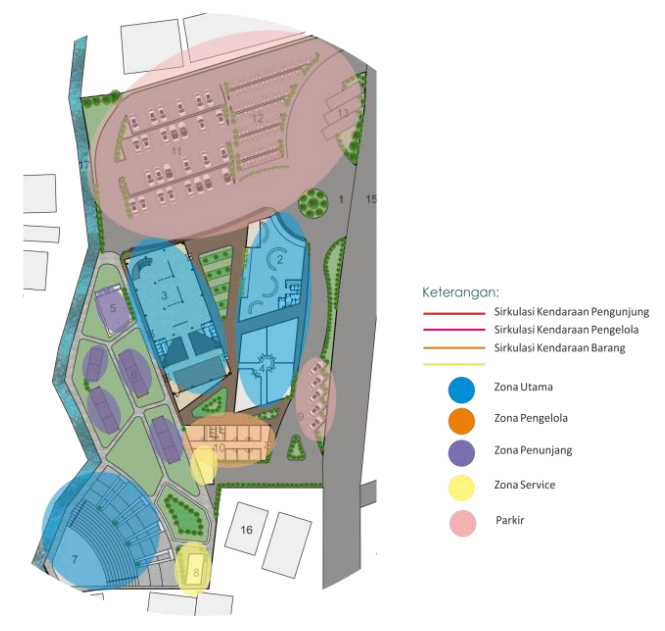

Gambar 3. Zonasi site

Sumber: Hasil analisis, 2018

Gambar 3 menjelaskan tentang pembagian zonasi pada site. Zona terbagi atas zona utama yang terdiri dari ruang galeri, ruang pertunjukan dan workshop. Zona pengelola, zona penunjang terdiri dari retail-retail, foodcourt, perpustakaan, dan zona service.

\section{Penerapan Konsep Edukasi pada Desain}

Edukasi dan kebudayan sangat behubungan karena keduanya saling berkesinambungan dan saling mendukung satu dengan yang lainnya. Tujuan edukasi adalah untuk melestarikan kebudayaan itu sendiri, dengan adanya edukasi atau pendidikan budaya dapat ditransfer dari satu generasi ke generasi berikutnya.

Dalam pengembangan konsep tugas akhir ini, pendekatan yang digunakan adalah edukasi. Pendekatan edukasi bertujuan untuk melestarikan nilai-nilai budaya yang ada. Dengan edukasi dapat menjadi sarana efektif untuk pengenalan seni dan budaya bagi generasi penerus sehingga seni budaya tidak punah dan tetap terlestarikan. Pusat kebudayaan tidak hanya sebagai wadah dalam mengapresiasi seni dan budaya, tetapi juga menjadi sarana pengenalan dan pembelajaran bagi masyarakat luas dalam memberikan suatu pengetahuan dan ilmu untuk mengenal suatu kebudayaan lokal, sehingga budaya tersebut tetap bertahan untuk kedepannya.

Menurut Widiantoro (2015), kriteria tata ruang yang edukatif harus mempertimbangkan empat faktor penting, yaitu kesempatan belajar yang luas, fleksibel, variatif, serta kejelasan orientasi. 
Konsep gubahan masa dalam proyek ini terdiri dari beberapa masa bangunan yang daimbil dari kebudayaan Pandeyan yang beragam dan menyebar. Sedangkan gubahan masa bangunan merespon bentukan site. Bentuk gubahan masa juga didapat dari bentuk organis ketupat yang menjadi simbol adat Kampung Pandeyan yaitu Bakdo Kupat yang bertujuan unyuk memasukan unsurunsur seni budaya pada setiap elemen sehingga akan mengedukasi penggunanya.

Menurut Sampouw et al. (2016), edukasi atau pendidikan bisa diperoleh dari banyak sarana baik secara formal yaitu sekolah, maupun nonformal yaitu membaca, menonton film, mendengarkan musik, bahkan melalui bersosialisasi. Pendidikan merupakan unsur yang penting untuk meningkatkan sumber daya manusia. Semakin tinggi pendidikan seseorang, maka akan tercermin tingkah laku, budi pekerti, serta cara pandang yang luas dibandingkan dengan orang yang berpendidikan lebih rendah. Edukatif adalah suatu kondisi yang memberikan pengetahuan, pemahaman dan pengajaran (Nur, 2015). Edukasi diwujudkan sebagai sarana penunjang, namun juga dapat mengajarkan kepada pengunjung untuk dapat 'belajar'. Edukasi dapat diwujudkan dengan adanya fasilitas yang bersifat mendidik.

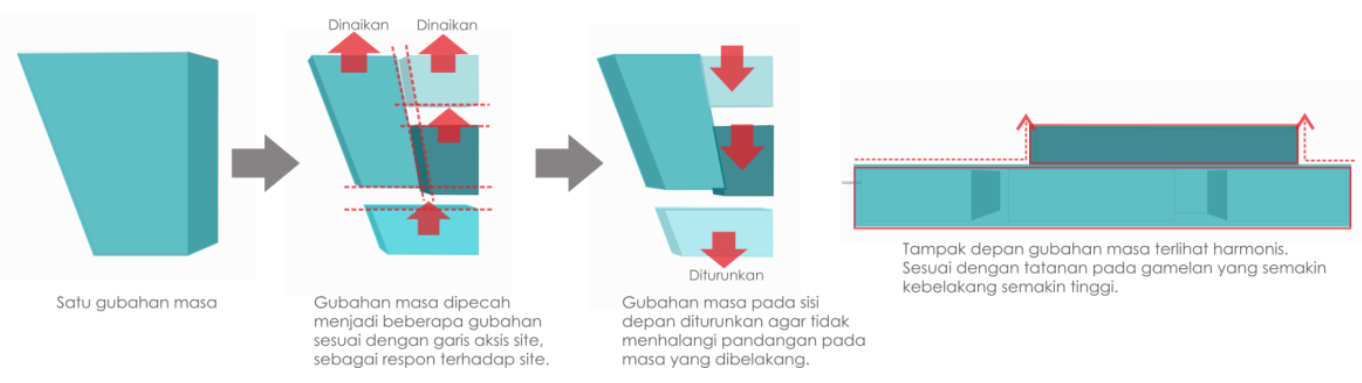

Gambar 4. Konsep gubahan masa

Sumber: Hasil analisis, 2018

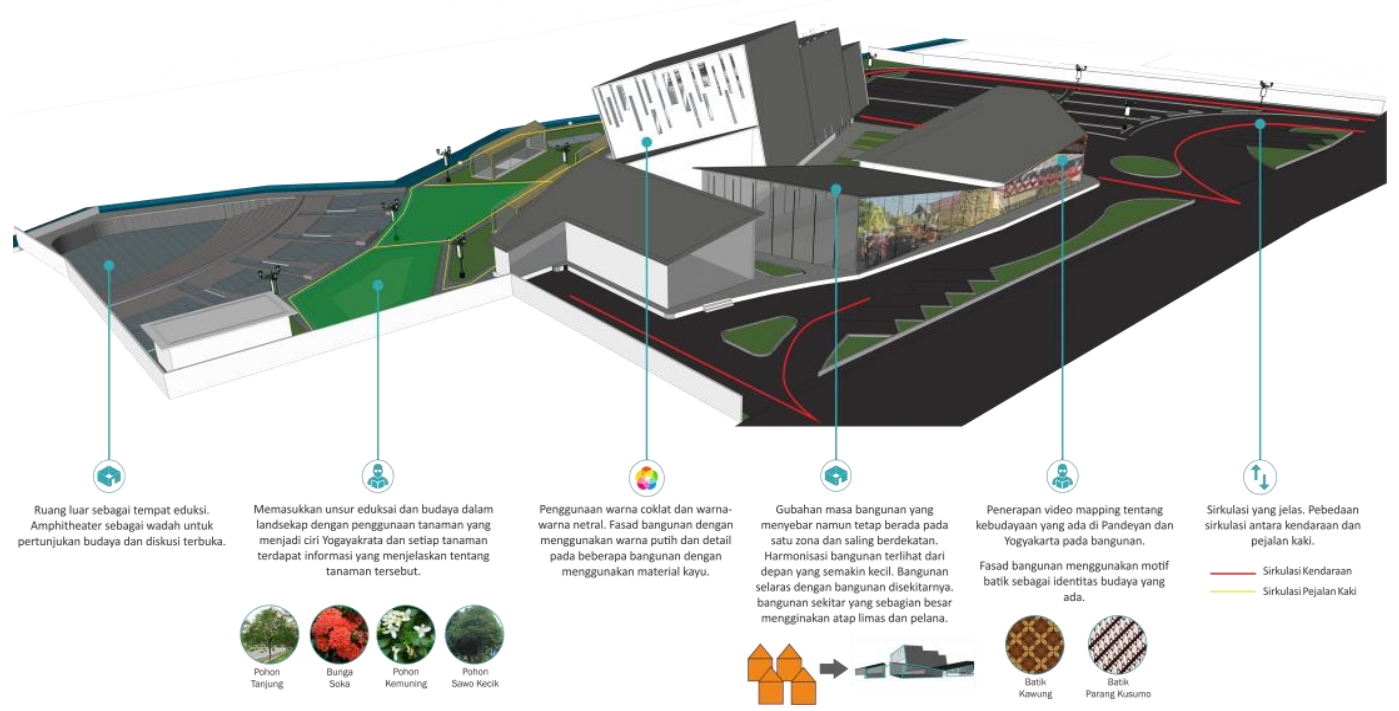

Gambar 5. Penerapan konsep gubahan masa

Sumber: Hasil analisis, 2018 
Fungsi bangunan dan penerapan unsur budaya pada setiap elemen bangunan terdapat pada detail-detail bangunan sebagai fasade. Konsep tentang budaya yang mengedukasi juga diterapkan dalam ruang luar berupa lansekap bangunan dengan tanaman khusus dan ruang luar yang dapat digunakan sebagai apresiasi budaya, seperti pameran atau bermain permainan tradisonal. Material yang digunakan adalah material lokal sehingga selaras dengan lingkungan sekitarnya.

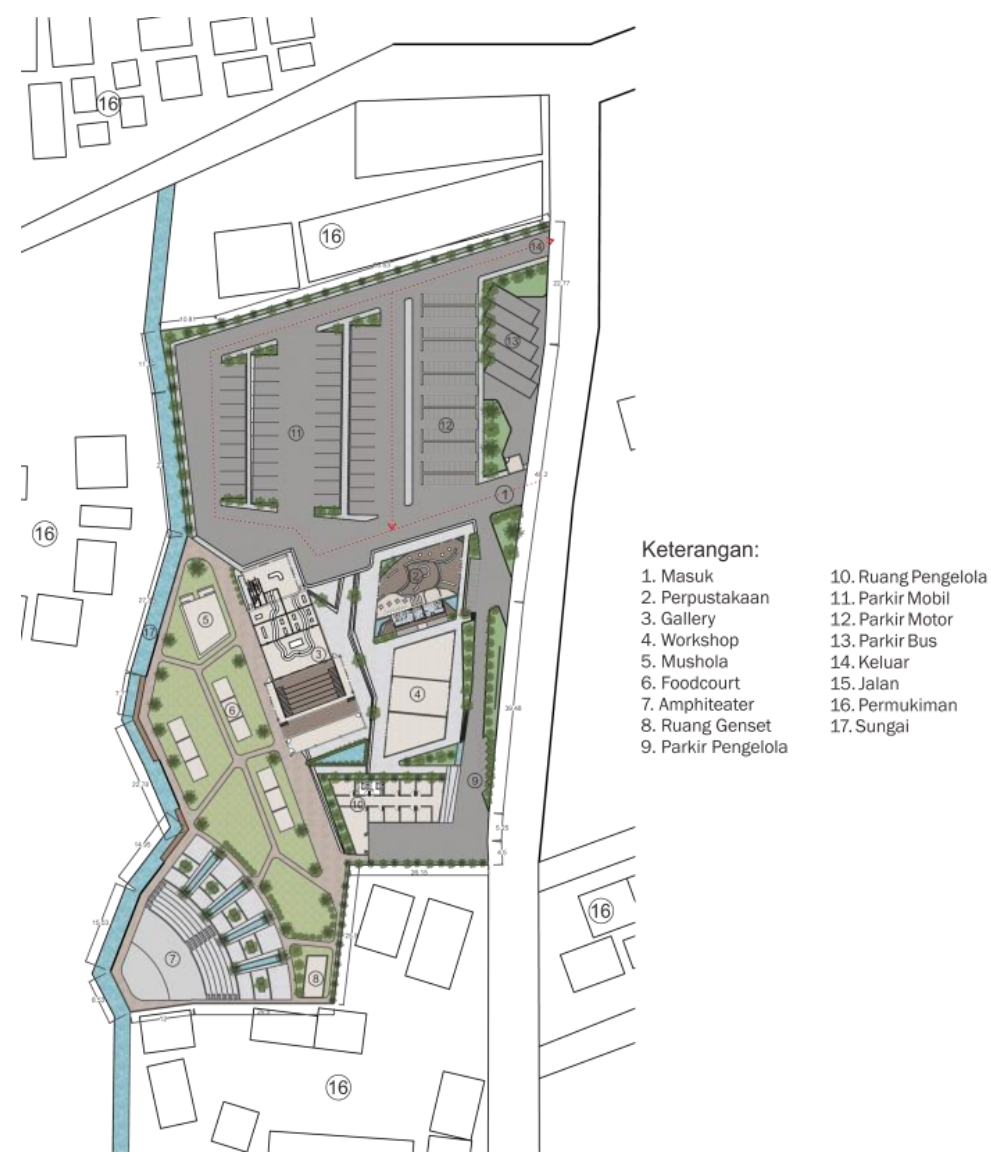

Gambar 6. Site plan dan sirkulasi Sumber: Hasil analisis, 2018

Sirkulasi yang jelas antara pengguna kendaraan dan pejalan kaki membuat pengunjung merasa nyaman dan aman. Sirkulasi service yang berbeda dengan sirkulasi pengguna cukup jelas. Kendaraan hanya berada pada sisi utara bangunan, untuk mencapai bangunan, pengguna harus berjalan kaki. Sirkulasi pejalan kaki akan memasuki setiap ruang, sehingga ruang-ruang yang ada akan berfungsi lebih maksimal.

\section{Kesimpulan}

Makalah ini merumuskan pentingnnya adanya pusat kebudayaan pada Kampung Pandeyan sebagai fasilitas bagi masyarakat dalam mengapresiasi seni dan budaya yang ada di kampung tersebut. Dengan demikian, seni dan budaya yang ada tetap terjaga dengan baik dan dapat menjadi warisan yang berharga bagi generasi penerus. 


\section{Daftar Pustaka}

Budianto, A.D.C. (2012). Pusat pengembangan seni wayang kulit di Yogyakarta (Tugas Akhir S1, Universitas Atma Jaya Yogyakarta, 2012. Tidak dipublikasikan).

Nur, Muhamad Abibakrin. (2015). Upaya edukatif pada program tentara manunggal membangun desa (TMMD) dalam meningkatkan partisipasi masyarakat. (Skripsi S1, Universitas Pendidikan Indonesia, 2015. Tidak dipublikasikan).

Ramdini, N.E., Sarihati, T., Salayanti, S. (2015). Perancangan interior pusat kebudayaan Yogyakarta. $e$ Proceeding of Art \& Design. Vol. 2, No. 2, Agustus 2015, 879-885.

Sampouw, I.E.P., Sondakh, J.A.R., Supardjo, S. (2016). Redesain perpustakaan daerah di Manado "penelusuran makna edukatif dan rekreatif dalam arsitektur". Jurnal Arsitektur DASENG, Vol. 5, No. 1, Mei 2016, 103-124.

Sugiyono. (2009). Metode penelitian kuantitatif, kualitatif dan $R \& D$. Bandung: Alfabeta.

Tylor, E.B. (2012). Primitive culture, researches into the development of mythology, philosophy, religion, language, art and customs, vol. 1 of 2 (classic reprint). London: Forgotten Books.

Widiantoro, Y.R. (2015). Landasan konseptual perencanaan dan perancangan agriculture edutainment park untuk anakanak di Bantul (Tugas Akhir S1, Universitas Atma Jaya Yogyakarta, 2015. Tidak dipublikasikan). 